\title{
Genetic and Epigenetic Changes in Mammary Epithelial Cells Identify a Subpopulation of Cells Involved in Early Carcinogenesis
}

\author{
H. Berman, J. Zhang, Y.G. Crawford, M.L. Gauthier, C.A. Fordyce, K.M. McDermott, \\ M. Sigaroudinia, K. Kozakiewicz, and T.D. TLSTY \\ Department of Pathology and UCSF Comprehensive Cancer Center, University of California at San Francisco, \\ San Francisco, California 94143-0511
}

\begin{abstract}
Morphologically normal foci of epithelial cells exhibiting p16 inactivation have been found in several tissues and may be precursors to cancer. Our previous work demonstrates that cells lacking $\mathrm{p} 16^{\mathrm{INK} 4 \mathrm{~A}}$ activity exhibit phenotypes associated with malignancy (Romanov et al. 2001). The acquisition of genomic instability occurs through the activation of telomeric and centrosomal dysfunction. Additionally, the activation of stress pathways such as COX-2 provides these cells with the mutagenic potential to survive adverse environments as well as the ability to migrate, evade apoptosis and immune surveillance, and summon sustaining vasculature. Examination of archived tissue from women with DCIS (ductal carcinoma in situ) reveals epithelial cells that overexpress markers of premalignant stress activation pathways and mirror the distinctive expression patterns of these markers observed in vitro. These epithelial cells are found within the premalignant lesion as well as in the field of morphologically normal tissue that surrounds the lesion. Here, we show that $16^{\mathrm{INK} 4 \mathrm{~A}}$-silenced vHMEC cells exhibit a gene expression profile which is distinct, reproducible, and extends beyond the changes mediated by $\mathrm{p} 16^{\mathrm{INK} 4 \mathrm{~A}}$ inactivation. The present work suggests that cells lacking $\mathrm{p} 16^{\mathrm{INK} 4 \mathrm{~A}}$ activity exhibit critical activities which allow cells to evade differentiation processes that would be expected to terminate proliferation. All of these properties are critical to malignancy. These events may be useful biomarkers to detect the earliest events in breast cancer.
\end{abstract}

\section{STUDYING CAUSAL EVENTS IN BREAST CANCER}

Studies of human mammary epithelial cells (HMEC) from healthy individuals are providing novel insights into how early epigenetic and genetic events affect genomic integrity and fuel carcinogenesis. Key epigenetic changes, such as the hypermethylation of the $16^{\mathrm{INK} 4 \mathrm{~A}}$ promoter sequences, create a previously unappreciated pre-clonal phase of tumorigenesis in which a subpopulation of mammary epithelial cells is positioned for progression to malignancy (Romanov et al. 2001; Tlsty et al. 2001). These key changes precede the clonal outgrowth of premalignant lesions and occur frequently in healthy, disease-free women. Understanding more about these early events should provide novel molecular candidates for prevention and therapy of breast cancer that target the process, instead of the consequences, of genomic instability. We highlight some of the key alterations that have been studied in HMEC in culture and relate them to events observed in vivo. Heroic efforts over the past three decades have provided culture systems that allow the isolation and propagation of HMEC (Hammond et al. 1984; Band and Sager 1989; Taylor-Papadimitriou et al. 1989; Kao et al. 1995). Understanding the contribution of specific genetic alterations to the transformation of these cells through the expression of viral oncoproteins and selected oncogenes is ongoing in many laboratories (Walen and Stampfer 1989; Foster and Galloway 1996; Kiyono et al. 1998; Hahn et al. 1999) and has increased our knowledge of oncogenesis. Studies in our laboratory have approached this question from a different perspec- tive, analyzing HMEC in the absence of introducing viruses or oncogenes.

Because over $90 \%$ of human cancers, including breast cancer, are of epithelial origin, we initiated our studies with the comparison of fibroblasts and epithelial cells from the same tissue, searching for differences in transformation-relevant signal transduction pathways. In contrast to human fibroblasts, HMEC do not exhibit a classic senescent arrest when grown in vitro (Romanov et al. 2001). HMEC obtained from normal human tissues contain a subpopulation of "variant" cells that are resistant to the negative growth signals that initiate a proliferative arrest (selection) in the majority of the HMEC population after several passages in culture (Brenner et al. 1998; Foster et al. 1998; Huschtscha et al. 1998). These variant HMEC (vHMEC), which become visible while the majority of the population is arrested in selection, lack p16INK4a activity, a critical regulator of cell cycle checkpoint control, and proliferate for an extended period of time with eroding telomeric sequences. These cells subsequently exhibit telomeric dysfunction and generate the types of chromosomal abnormalities seen in the earliest lesions of breast cancer (Romanov et al. 2001). Similar subpopulations are not observed in isogenic mammary fibroblasts (Romanov et al. 2001). These differences between epithelial cells and fibroblasts may provide new insights into the mechanistic basis of neoplastic transformation. The existence of this subpopulation of vHMEC cells, their ability to grow past proliferation barriers, and the accompanying acquisition of telomeric and centrosomal dysfunction may be pivotal events in the earliest steps of carcinogenesis, allowing the acquisition of multiple, fundamental genetic changes necessary for oncogenic evolution. 

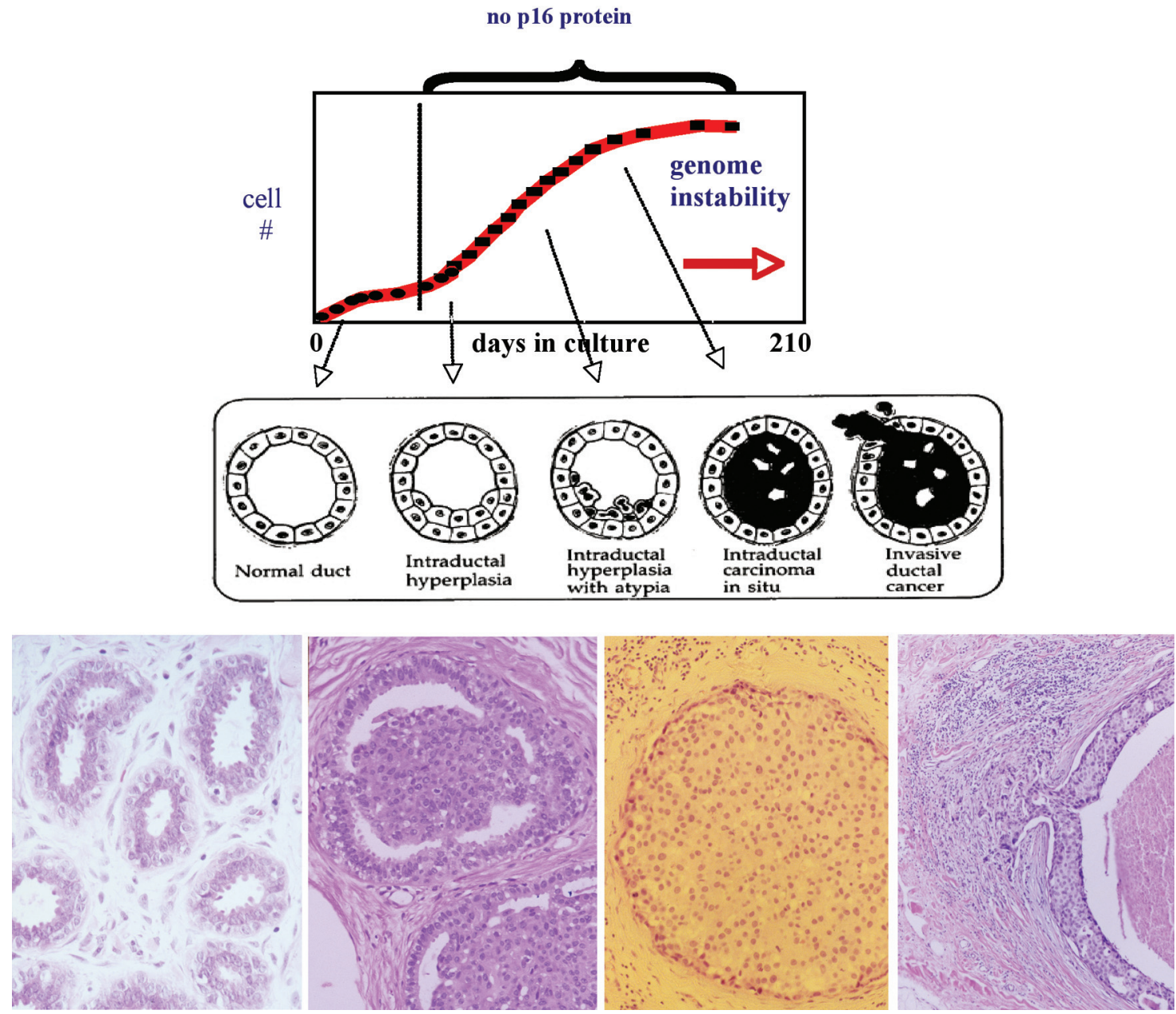

Figure 1. Hypothetical relationship between epithelial cells in vitro and in vivo. The top panel illustrates the growth curve for HMEC isolated from reduction mammoplasties. The (pre-selection) cells increase in number for $\sim 20$ population doublings when grown in culture and then enter a proliferation arrest (selection) whose termination is noted by the vertical line. Clonal isolates emerge from the arrested cell lawn and continue proliferation for $\sim 3-5$ months in culture until there is no further increase in cell number. These post-selection HMEC (variants) have no detectable p16 protein and contain hypermethylated p16 promoter sequences. 10-20 population doublings prior to an obvious population growth plateau, the cells acquire chromosomal changes (genome instability). We postulate that the growth of vHMEC in vitro may mimic the different premalignant stages of breast cancer (lower panels) as illustrated by the arrows.

The long-sought goal of many studies has been to identify the molecular (causal) changes that underlie progression of normal cells to malignancy with hopes that such information will provide selective targets for effective treatment of the disease. In this review, we describe the cellular and molecular evolution of HMEC in vitro and illustrate striking similarities with the evolution of mammary cells as they progress from normal to premalignant to malignant in vivo (Fig. 1).

\section{CHARACTERIZATION OF HMF AND HMEC IN VITRO: IDENTIFICATION OF A SUBPOPULATION OF VARIANT EPITHELIAL CELLS}

Fibroblasts have provided the paradigm for cell senescence in culture. It is well known that human fibroblasts undergo a limited number of cell divisions prior to activating specific cell cycle checkpoints and entering into an irreversible arrest (variously termed the Hayflick limit [Hayflick 1965], irreversible replicative senescence, and mortality stage 1 [M1]). Human mammary fibroblasts (HMF) from healthy individuals were grown as previously described (Hammond et al. 1984) and characterized. Similar to previous studies in human skin fibroblasts (Hammond et al. 1984; Walen and Stampfer 1989; Brenner et al. 1998; Huschtscha et al. 1998; Kiyono et al. 1998), the HMF populations undergo a limited number of population doublings prior to entering a proliferative plateau (Fig. 1) (Romanov et al. 2001). The cells enlarge in size, flatten in shape, vacuolate, and express senescence-associated $\beta$-galactosidase (SA- $\beta$-gal; Romanov et al. 2001). Low incorporation of bromodeoxyuridine (BrdU) and minimal expression of MCM2 protein indi- 
cated a low proliferative index. Additionally, Annexin-V staining indicated a low death index. Further characterization demonstrates that human foreskin fibroblasts and HMF both (1) maintain genomic integrity (Walen and Stampfer 1989; Romanov et al. 2001); (2) maintain intact cell cycle checkpoint control (data not shown); (3) exhibit a $2 \mathrm{~N}$ to $4 \mathrm{~N}$ DNA content ratio of $\geq 4$ at the growth plateau (Romanov et al. 2001); and (4) have a mean telomere restriction fragment (TRF) length that is similar at senescence (Romanov et al. 2001). By the morphological, behavioral, and molecular criteria described above, HMF could be said to senesce in a manner similar to human skin fibroblasts. If senescence is the result of a signal from shortened telomeres, as has been previously postulated (Bodnar et al. 1998), one would predict that the expression of the catalytic subunit of telomerase, hTERT, would allow cells to bypass "senescence" and continue proliferating. This prediction has been realized in the examination of human fibroblasts expressing hTERT (Bodnar et al. 1998; Jiang et al. 1999); they exhibit an extended life span without acquiring properties of transformed cells (Jiang et al. 1999).

At first glance, it appeared that HMEC do not conform to this paradigm of senescence. In contrast to fibroblasts, HMEC obtained from normal human tissue demonstrate two growth phases (Fig. 1). After an initial phase of active growth ( 15-20 population doublings), HMEC exhibit a growth plateau previously termed senescence, selection, or M0 (Hammond et al. 1984; Foster and Galloway 1996; Huschtscha et al. 1998). At this time, the majority of the cell population is arrested in the $G_{1}$ phase of the cell cycle. When the flasks containing arrested HMEC are cultured in serum-free media (MCDB 170), colonies of small, proliferative epithelial cells become visible. These cells (post-selection or variant cells) are capable of undergoing an additional $20-50$ population doublings before terminating in a population growth plateau that confusingly was also termed senescence or, alternatively, M1 (Foster and Galloway 1996; Huschtscha et al. 1998; Kiyono et al. 1998). On the basis of these observations, it was previously postulated that senescence in HMEC involved two steps, with some cells transitioning past the initial plateau, proliferating, and ultimately entering senescence several months later (Foster and Galloway 1996). We now appreciate that the two growth phases represent the growth of two independent populations of mammary epithelial cells (described below) and that neither population enters replicative senescence as classically defined by experiments in human skin fibroblasts. In keeping with Stampfer's original designation (Hammond et al. 1984), we also term the plateau in which cells containing unmethylated $p 16^{I N K 4 a}$ undergo a proliferative arrest, selection. However, because of the recent appreciation for the origin of the (post-selection) HMEC containing hypermethylated $p 16^{I N K 4 a}$ promoter sequences, and to avoid a mechanistic implication of their behavior in vivo, we call the $p 16^{I N K 4 a}$-deficient cells variant human mammary epithelial cells or vHMEC.

To analyze apparent cell-specific differences, we characterized the two in vitro population-growth plateaus, the first plateau and the second plateau from healthy individ- uals grown as previously described (Hammond et al. 1984), and compared them to the replicative senescence described in human skin fibroblasts. Similar to previous studies in human skin fibroblasts and HMEC (Hammond et al. 1984; Walen and Stampfer 1989; Brenner et al. 1998; Huschtscha et al. 1998; Kiyono et al. 1998), the epithelial cell populations undergo a limited number of population doublings prior to entering a proliferative plateau (Fig. 1) (Romanov et al. 2001). Just as seen with the fibroblasts described above, the cells enlarge in size, flatten in shape, vacuolate, and express SA- $\beta$-gal (Romanov et al. 2001). Low incorporation of BrdU and minimal expression of MCM2 protein indicated a low proliferative index. Additionally, Annexin-V staining indicated a low death index. Further characterization demonstrated that pre-selection HMEC (1) maintain genomic integrity (Walen and Stampfer 1989; Romanov et al. 2001); (2) maintain intact cell cycle checkpoint control (data not shown); (3) exhibit a $2 \mathrm{~N}-4 \mathrm{~N}$ DNA content ratio of $\geq 4$ at the growth plateau (Romanov et al. 2001); and (4) have a mean TRF length that is similar to that of human skin fibroblasts and HMF at replicative senescence (Romanov et al. 2001). Although the morphological, behavioral, and molecular criteria described above suggested that HMEC had entered replicative senescence in a manner similar to human skin fibroblasts, the expression of telomerase did not have a comparable outcome. Experiments (Kiyono et al. 1998; Stampfer et al. 2001) have demonstrated that expression of hTERT in these cells does not prevent their entry into the first growth plateau as described for fibroblasts. This demonstrates that the first growth plateau exhibited by HMEC grown in tissue culture does not correspond to the classic telomere-length-based replicative senescence. As described below, it is only in the epithelial cells which lack $p 16^{I N K 4 a}$ expression that telomerase can "immortalize" a population (Kiyono et al. 1998; Stampfer et al. 2001). Intriguingly, recent experiments with fibroblasts also suggest that only fibroblast populations with low p16 $6^{I N K 4 a}$ activity can be immortalized by expression of telomerase (Benanti and Galloway 2004). If this is so, it raises the question of why fibroblasts do not contain a subpopulation of cells that bypasses the imposed arrest, as is seen in the epithelial population from the same individual.

Strikingly, HMEC and HMF appeared to differ in their ability to spontaneously overcome the observed proliferation barriers by several orders of magnitude. In skin fibroblasts, the terminal growth plateau, senescence, can last for years (>3 years; T.D. Tlsty, unpubl.). Cells remain viable if fed routinely (Romanov et al. 2001), and the frequency of spontaneous emergence is $<10^{-9}$ (data not shown; Romanov et al. 2001). Similarly, HMF fail to produce proliferating cells from senescence even after 5 months in continuous culture $\left(<6 \times 10^{-7}\right.$, data not shown) (Romanov et al. 2001). In contrast to fibroblasts and consistent with previous reports (Hammond et al. 1984; Huschtscha et al. 1998), epithelial populations maintained at the first plateau sporadically contain clusters of small, refractile cells $\left(\sim 10^{-4}\right.$ to $\left.10^{-5}\right)$ that continue to proliferate. Both the epithelial cells growing prior to the selection plateau (pre-selection or HMEC) and the epithelial cells growing after the selection plateau (post- 


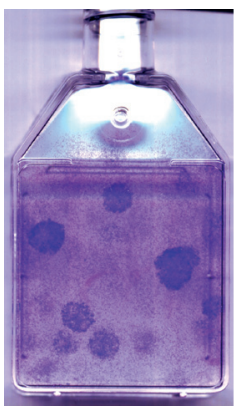

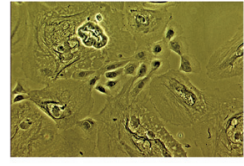

Phase

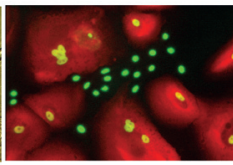

$\mathrm{p} 16^{\mathrm{INK} 4 \mathrm{~A}}$
Figure 2. Visualization of vHMEC at selection. HMEC are plated in flasks prior to entering the proliferation barrier. Cells propagate, enter the first plateau, and change morphology, becoming large and flat. After $\sim 2$ weeks at the plateau, clonal expansions of small, proliferating cells (vHMEC) are visible (Phase, middle panel). ICC shows them to be devoid of $\mathrm{p} 16^{\mathrm{INK} 4 \mathrm{a}}$ (red, right panel). Green fluorescence identifies cell nuclei. The flask (left panel) was seeded with $10^{5}$ cells and fed routinely until colonies were visible. The cells were stained with Wright's solution. The number of colonies allows measurement of the clonal events.

selection HMEC or vHMEC) exhibited typical heterogeneous expression of cytokeratins when examined by immunocytochemistry (ICC) (data not shown; Taylor-Papadimitriou et al. 1989). For these and other reasons, the variant cells were believed to be the continued growth of the earlier population. As noted previously by several laboratories, HMEC emerging from the first populationgrowth plateau lack expression of the $p 16^{I N K 4 a}$ protein (Fig. 2) (Brenner et al. 1998; Foster et al. 1998; Huschtscha et al. 1998; Ramirez et al. 2001) due to the hypermethylation of the $p 16^{I N K 4 a}$ promoter sequences. This observation provided a viable explanation for the continued growth of the variant cells in culture.

\section{PROMOTER HYPERMETHYLATION OF THE $p 16^{I N K 4 a}$ GENE AND CANCER}

The lack of $p 16^{I N K 4 a}$ activity in the variant HMEC is an intriguing finding (Brenner et al. 1998; Foster et al. 1998; Huschtscha et al. 1998) because it provides an epigenetic marker for the vHMEC population. Although the role of epigenetic $p 16^{I N K 4 a}$ silencing in the growth of the vHMEC cells has been relatively uncharacterized, the role of $p 16^{I N K 4 a}$ silencing in the carcinogenic process has been extensively studied. The $p 16^{I N K 4 a}$ gene product was initially isolated by two-hybrid screening for proteins associated with cyclin-dependent kinase 4 (Serrano et al. 1993) and was found to be a member of a family of proteins that bind and block the activity of cyclin D/cdk4 complexes and induce cell cycle arrest. Forced expression of $p 16^{I N K 4 a}$ protein induces a $\mathrm{G}_{1}$ arrest that is dependent on functional retinoblastoma protein $(\mathrm{Rb})$ (Medema et al. 1995). Homozygous deletion of the chromosomal region containing $p 16^{I N K 4 a}$ (and an additional family member, $p 15^{I N K 4 b}$ ) is the most common genetic event in primary tumors (Cairns et al. 1994). The dissection of the contribution of these two loci in the initiation and progression of different cancers has demonstrated that loss of $p 16^{I N K 4 a}$ alone (with retention of $\mathrm{p} 19^{\mathrm{Arf}}$ ) leads to tumor predisposition in mice (Krinferpot et al. 2001). These animals have been shown to be highly susceptible to spontaneous and carcinogen-induced malignancy (Sharpless et al. 2001). The $p 16^{I N K 4 a}$ gene can be inactivated by translocations, by mutations at many sites, and by hypermethylation (Gonzalez-Zulueta et al. 1997). Point mutation in intron 2 (Asp-153) has been identified in tumors that leave cdk4 binding intact while aborting inhibition of cdk activity (Yang et al. 1996). Other temperature-sensitive mutations, Gly-101 $\rightarrow$ Trp and Val$126 \rightarrow$ Asp, abrogate binding to CDK4/6 and have been demonstrated to increase the fraction of $\mathrm{G}_{1}$ cells after transfection (Parry and Peters 1996). The hypermethylation of $p 16^{I N K 4 a}$ promoter sequences is also seen in over $20 \%$ of breast cancers.

The methylation of the $p 16^{I N K 4 a}$ gene locus (and the concomitant silencing of $p 16^{I N K 4 a}$ activity) is an effective way of modulating gene expression (Gonzalez-Zulueta et al. 1997; Baylin and Herman 2000). In the mammalian genome, methylation can occur at $\mathrm{CpG}$ islands that are found in the proximal promoter regions of genes (Baylin and Herman 2000). The change in gene expression is heritable and is tightly linked to the formation of transcriptionally repressed chromatin structure. Cancers often exhibit changes in methylation in gene promoter sequences that are associated with loss of tumor suppressor function (Nguyen et al. 2001), providing an alternative to mutations that disrupt gene function. The importance of $\mathrm{CpG}$ island hypermethylation in cancer is obvious, given the frequency of the process and the genes involved. The majority of tumor suppressor genes that cause genetic predisposition to cancer can be silenced by hypermethylation in nonfamilial cancers. The genes that can be methylated include repair genes (MLH1, GST3), cell cycle inhibitors ( $\left.p 16^{I N K 4 a}, \mathrm{p} 15, \mathrm{p} 14 \mathrm{ARF}\right)$, tumor suppressor genes (VHL, BRCA1), tissue remodeling enzymes and structures (TIMP3, E-cadherin), and receptors (estrogen receptor), to name a few (Baylin and Herman 2000). Methylation changes often precede the mutagenic events that drive tumor progression.

\section{CHARACTERIZATION OF vHMEC IN VITRO: ACQUISITION OF GENOMIC INSTABILITY VIA TELOMERIC DYSFUNCTION}

After they are observed, vHMEC undergo exponential growth that usually extends for several months (Fig. 1, growth past the vertical line), before entering a second population growth plateau (Fig. 1, agonescence). This plateau is critically different from the arrested state that terminates the proliferation of the HMEC population (P1 or first plateau). Although previous studies have referred to this second plateau as senescence or M1, these cells display attributes more similar to cells in crisis, than senescence. vHMEC at this stage are heterogeneous in size and morphology and demonstrate SA- $\beta$-gal staining (data not shown). Furthermore, they continue to incorporate BrdU and retain high levels of MCM2 protein $(>50 \%$ of nuclei strongly staining for MCM2). Upon FACS analysis, the $2 \mathrm{~N}$ to $4 \mathrm{~N}$ DNA ratio is approximately 1 , similar to a population of cells in crisis (Romanov et al. 2001). This high proliferative index is counterbalanced by an in- 
crease in cell death such that the total number of cells remains constant. A significant fraction $(\sim 20 \%)$ of epithelial cells at the second plateau stain with Annexin-V, an indicator of cell death. In contrast, $<1 \%$ of isogenic senescent HMF (or HMEC at the first plateau) are Annexin-V-positive. Thus, vHMEC at the second plateau are unlike HMEC at the first plateau or fibroblast cells at senescence (Romanov et al. 2001).

The cytogenetic analysis of vHMEC at selected passages demonstrates that gross chromosomal abnormalities appear in virtually every metaphase spread as the cells approach the second growth plateau (Romanov et al. 2001). In all cases, the abnormalities accumulate rapidly beginning 10-20 population doublings before the final passage of cells (Fig. 3) and coincide with slowing of the proliferation rates. In these cells, both the percentage of abnormal metaphases and the number of abnormalities per metaphase increase. The abnormalities include multiple translocations, deletions, other rearrangements, telomeric associations, polyploidy, and aneuploidy. Substantial polyploidy $(\sim 25-35 \%)$ is detected by flow cytometric analysis at final passages of vHMEC. Multipolar mitoses are often observed. The accumulation of chromosomal abnormalities is independent of donor age (range, 16-50 years) and total proliferative potential of the epithelial populations (range, 30-60 PD). Characterization of these abnormalities has been described previously (Romanov et al. 2001).

Shortening of telomeres and their associated uncapping has previously been suggested to mediate chromosomal instability through the production of dicentric chromosomes (Van Steensel et al. 1998). Resolution of dicentric chromosomes by chromosome breakage generates translocations, deletions, and duplications. Failure to resolve them can generate anaphase bridges, failed cytokinesis, and polyploid cells. These abnormalities are detected frequently in vHMEC at the second plateau (Romanov et al. 2001). Thus, the subpopulation of vHMEC that emerge

\section{Accumulation of structural chromosomal abnormalities in late passage mammary epithelial cell populations}

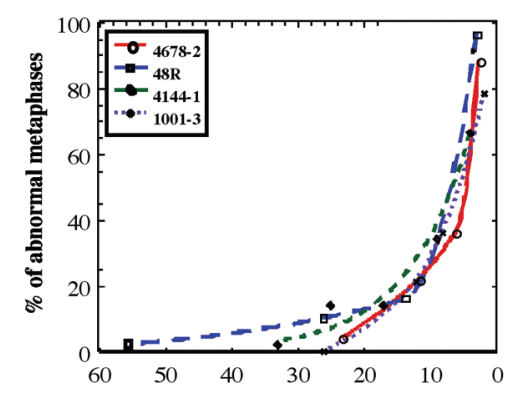

Population doublings before second growth plateau

Figure 3. Chromosomal instability in vHMEC. The kinetics of accumulation of chromosomal abnormalities is diagramed as a function of time. The percentage of metaphase spreads with structural chromosomal abnormalities was plotted as a function of the number of population doublings before the cells entered the population growth plateau (agonescence), designated 0 . Each line represents analysis of cells from different women. The women ranged in age from 16 to 50 years old. Karyotypes were performed at each point that comprises the given line. from the first proliferation barrier ultimately exhibit telomeric dysfunction. Although vHMEC at the second plateau exhibit many of the cellular characteristics of viral oncoprotein-induced crisis, spontaneous immortalization of variants (an important distinguishing hallmark of crisis) has yet to be detected. In addition, the p53 gene sequence is wild type in these cells and still functional (Romanov et al. 2001). Because of these (and other) differences (Tlsty et al. 2004), we have called these cells "agonescent" to distinguish them from cells in crisis. The Latin root "agon" defines a violent struggle that precedes death or a strong sudden display. The most prominent attributes of the late-passage vHMEC are their dramatic accumulation of chromosomal rearrangements and the dynamic state of proliferation and death.

The vHMEC described in this model system and the existence of an agonescent stage of proliferation provide a compelling argument for acquisition of massive random genomic instability that precedes clonal outgrowth of tumor cells. Indeed, at the point in culture when virtually all of the vHMEC cells exhibit chromosomal abnormalities via karyotypic analysis, analysis by comparative genomic hybridization $(\mathrm{CGH})$ shows the population to be in a diploid non-rearranged state (T.D. Tlsty et al., in prep.). This is because CGH assesses clonal chromosomal changes that are present in a large fraction of the cell population and cannot detect random, non-clonal changes. It is intriguing to speculate that the relatively few chromosomal structural abnormalities observed in hyperplasias and atypical hyperplasias (Burbano et al. 2000), and the transition to the dramatic increase of genomic instability detected in carcinoma in situ (CIS) in vivo using CGH analysis (Berg and Hutter 1995; Pandis 1995), are reflective of a pre-clonal phase of growth followed by clonal expansion in CIS. Therefore, this model system may have uncovered a previously unappreciated pivotal phase in tumorigenesis. In this pre-clonal phase, epithelial cells have the potential to acquire multiple, random chromosomal changes that provide fuel for clonal expansion.

\section{CHARACTERIZATION OF VHMEC IN VITRO: ACQUISITION OF GENOMIC INSTABILITY VIA CENTROSOMAL DYSFUNCTION}

As described previously, many vHMEC exhibit multipolar mitoses as they approach the second plateau, agonescence. To better understand the mechanism responsible for generating cells with more than two centrosomes, we analyzed HMEC obtained from healthy, disease-free women with no predisposition to breast cancer. As these cells are propagated in culture, we observed that vHMEC accumulated centrosome-related (e.g., aneuploidy) genomic abnormalities (Romanov et al. 2001; Tlsty et al. 2001). We demonstrated that, in contrast to HMEC, vHMEC have uncoupled centrosome duplication and DNA replication cycles, and this uncoupling was due to loss of expression of the tumor suppressor protein $\mathrm{p} 16^{\mathrm{INK} 4 \mathrm{a}}$. We also showed that generation of cells with more than two centrosomes was a conditional phenotype, dependent on the inhibition of DNA synthesis. Further- 
more, loss of $\mathrm{p} 16^{\mathrm{INK} 4 \mathrm{a}}$ activity and consequent loss of kinase regulation were shown to result in uncoupling of these two cycles in other cell types (i.e., normal diploid human fibroblasts), demonstrating that this is a general role for $\mathrm{p} 16^{\mathrm{INK} 4 \mathrm{a}}$. Finally, we demonstrated that production of cells with more than two centrosomes gave rise to an aneuploid karyotype.

These results describe a new function of $\mathrm{p} 16^{\mathrm{INK} 4 \mathrm{a}}$ and further demonstrate the importance of $\mathrm{p} 16^{\mathrm{INK} 4 \mathrm{a}}$ in the maintenance of normal cellular properties. In this study, p $16^{\mathrm{INK} 4 \mathrm{a}}$ activity was found to be necessary to couple the centrosome duplication and DNA replication cycles. The coupling of these cycles is critical to ensure that the DNA content and the centrosome organelle are duplicated once and only once during the cell cycle. HMEC, with functional $\mathrm{p} 16^{\mathrm{INK} 4 \mathrm{a}}$, have coupled centrosome and DNA duplication cycles. Suppression of $\mathrm{p} 16^{\mathrm{INK} 4 \mathrm{a}}$ expression was sufficient to relax this control. This conclusion was supported by similar results obtained in multiple cell types (i.e., HMEC, HMF, and HeLa). The uncoupling of the centrosome duplication and DNA replication cycles and subsequent generation of more than two centrosomes was immediately unmasked under conditions that transiently inhibit DNA synthesis and was gradually unmasked during standard growth in culture. This finding offers an explanation for the observed accumulation of centrosome abnormalities in vHMEC during their life span in culture. As vHMEC proliferate in culture, they are increasingly exposed to internal signals (i.e., telomere shortening) and external signals (i.e., oxidative stress) leading to cell cycle checkpoint responses. We hypothesize that these signals result in transient inhibition of DNA synthesis, thereby providing the opportunity for vHMEC to accumulate more than two centrosomes as they mature in culture.

In addition to well-documented effects on genomic integrity, our data suggest that $\mathrm{p} 16^{\mathrm{INK} 4 \mathrm{a}}$ plays a significant role in maintaining cellular integrity via its regulation of centrosome biology. Because the centrosome is directly responsible for instituting proper polarity and microtubule function, abnormal centrosomal function has a direct effect on these properties and, hence, cellular integrity. Loss of proper cell polarity is one of the initial alterations noted in premalignant cells. Although many studies have focused on the role of $\mathrm{p} 16^{\text {INK4a }}$ in initiating a $G_{1} / S$ DNA replication cell cycle checkpoint, this study is the first to suggest a role for $\mathrm{p} 16^{\mathrm{INK} 4 \mathrm{a}}$ in cellular integrity as well as genomic integrity.

One hallmark of cancer is the accumulation of genomic abnormalities. Aneuploidy is the most frequently observed genomic abnormality and has been shown to occur early in progression, often accompanying premalignant lesions. Aneuploidy is also seen in histologically normal tissue, strongly suggesting that genomic instability is involved in the earliest stages of tumorigenesis (Deng et al. 1996; Larson et al. 1998, 2002; Lakhani et al. 1999; Li et al. 2002). The origin of aneuploidy in these premalignant lesions is unknown. Theodor Boveri hypothesized almost 100 years ago that multipolar mitoses were responsible for genomic abnormalities (Boveri 1914; Boveri et al. 1929). A more modern interpretation of this hypothesis is that events resulting in more than two centrosomes can lead to multipolar spindles and to improper segregation of the sister chromatids, leading to aneuploidy. The recent discovery of more than two centrosomes in premalignant and malignant lesions of the breast and their correlation with aneuploidy has provided new support for Boveri's hypothesis (Lingle et al. 1998, 2002; Lingle and Salisbury 1999; Salisbury 2001). However, it is still unclear whether centrosome abnormalities drive genomic instability or are merely a marker of cells with genomic abnormalities (Duensing 2005). Our studies are the first to take genomically intact cells with normal numbers of centrosomes, generate more than two centrosomes in these cells, and subsequently demonstrate that they obtain multipolar mitotic spindles and an aneuploid karyotype. These results strongly support the conclusion that centrosome amplification does indeed cause genomic instability.

\section{GENE EXPRESSION PROFILING OF HMEC AND vHMEC IDENTIFIES DIFFERENCES IN EXPRESSION}

To further characterize the vHMEC, we compared the expression profiles of isogenic sets of HMEC and vHMEC. Total RNA from pre-selection HMEC was compared to RNA from both mid and late passages of vHMEC using two-color cDNA microarrays (chip content and methods available at http://dir.niehs.nih.gov/ microarray). Following this analysis, we identified several genes that were differentially expressed between preselection cells and mid- or late-passage vHMEC. One of these genes, prostaglandin-endoperoxide synthase 2 (COX-2), was significantly induced (average, 6.3-fold). We have verified this observation in multiple populations of HMEC using western analysis and immunocytochemistry (Crawford et al. 2004). Subsequent studies demonstrate that this increase in COX-2 expression is causal for phenotypes often associated with malignant cells, such as an increase in angiogenesis, invasion, and proliferation, and a decrease in apoptosis (Crawford et al. 2004).

Strikingly, the gene expression profiles obtained from multiple vHMEC samples each share a significant number of changes (Fig. 4). These changes identify the variant HMEC population as a distinct subset of cells rather than a random outgrowth of mutant cells.

\section{THE ORIGIN OF VHMEC: VARIANT MAMMARY EPITHELIAL CELLS ARE DETECTED IN VIVO}

To determine whether cells with characteristics of variant HMEC (inactive $p 16^{I N K 4 a}$, overexpression of COX-2, and increased genomic instability) exist in vivo in healthy women, we took several approaches. Using the Luria-Delbrück fluctuation analysis (Luria and Delbrück 1943), we demonstrated that the vHMEC are generated (or exist) prior to the first plateau and do not arise through adaptation (Tlsty et al. 1989; Holst et al. 2003). Since the silencing (most often by methylation; Brenner et al. 1998; Foster et al. 1998; Huschtscha et al. 1998) of the important cell cycle inhibitor $p 16^{I N K 4 a}$ is a critical distinguishing characteristic of the vHMEC, we also analyzed morphologically normal tissue from reduction mammoplasties us- 

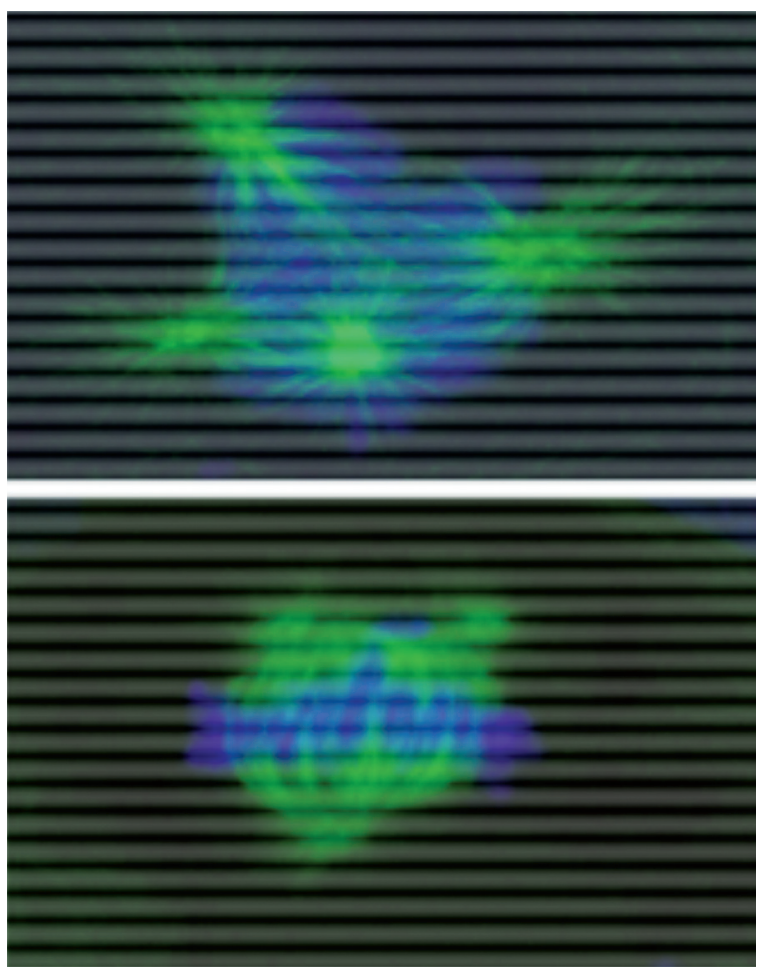

Figure 4. Multipolar mitosis in vHMEC generated via centrosomal dysfunction. Centrosome number was determined by immunocytochemistry with an antibody recognizing the centrosome-associated $\gamma$-tubulin protein (centrosome marker, red). Note the multipolar mitosis.

ing solution-based methylation-specific PCR to determine whether they contained detectable quantities of cells with $p 16^{I N K 4 a}$ promoter methylation. Using techniques that have previously been developed to detect methylated sequences in paraffin-embedded tissues (Herman et al. 1996, 1997), we measured the level of p16 $6^{I N K 4 a}$ promoter methylation in histological samples in collaboration with Drs. Steve Baylin and James Herman of Johns Hopkins University. Of 15 samples, 4 demonstrated methylated $p 16^{I N K 4 a}$ promoter sequences (Holst et al. 2003). Since the removal of tissue from the histological preparations includes both the epithelial cells of the mammary ducts and the stromal cells of the surrounding tissue, we additionally sought a method that would enable us to visualize the HMEC cells embedded in their natural tissue architecture. For this purpose, we collaborated with Dr. Gerard Nuovo, who developed an in situ method for detecting methylated sequences in histological sections from tumors (Nuovo et al. 1999). Ten samples of histological preparations of reduction mammoplasty tissue were examined for cells that contain methylated $p 16^{I N K 4 a}$ promoter sequences. Three of the ten samples demonstrated the unequivocal presence of cells (foci) that gave a positive signal, and were mapped using a novel method developed for the purpose of displaying multiple sets of data in the context of whole tissue (Holst et al. 2003). Close examination of the samples revealed that the cells producing a positive signal were luminal epithelial cells. Neither myoepithelial cells nor stromal cells produced positive signals in any of the samples analyzed. These data demonstrate that epithelial cells with hypermethylation of the $p 16^{I N K 4 a}$ promoter sequences exist as foci in morphologically normal tissue of disease-free women (Holst et al. 2003).

Although the in situ methylation-specific PCR assay provided evidence that epithelial cells with a distinguishing characteristic of vHMEC existed in morphologically normal tissue, the assay is too difficult and laborious to apply to large samples. For this purpose, we sought to assess other characteristics of vHMEC in vitro that may also be concomitantly expressed in the foci in vivo. One goal of the expression profile analysis was to identify such distinguishing characteristics of variant cells for the purpose of then examining their expression in vivo. To determine whether the increased expression of COX-2 that is seen in a fraction of the cells containing p16 hypermethylation in vitro is also present in vivo, we analyzed serial histological sections of human mammary tissue for colocalization of these markers (Crawford et al. 2004). Examination of the seven cases that were negative for cells with $\mathrm{p} 16^{\mathrm{INK} 4 \mathrm{a}}$ hypermethylation did not exhibit intense staining of COX-2. In contrast, examination of the three cases that were positive for cells containing p16 $6^{\text {INK4a }}$ hypermethylation exhibited areas of intense staining for COX-2 expression in adjacent serial slides. This intense staining colocalized with the areas of p16 promoter hypermethylation and extended to the adjacent areas. Maps were generated to demonstrate the localization of COX-2 in relation to $\mathrm{p} 16^{\mathrm{INK} 4 \mathrm{a}}$ hypermethylation (Crawford et al. 2004). Further analysis of these regions using an in situ hybridization technique has found them to also have shorter telomeres when compared to other areas of the same slide (C.A. Fordyce et al., in prep.).

The colocalization of intense COX-2 staining in cells with hypermethylated p16 sequences has important implications for the initiation and progression of malignancy in this tissue. COX-2 protein is instrumental in prostaglandin synthesis, and increased expression in tumor cells is accompanied by several phenotypes that are critically relevant to cancer development (Howe et al. 2001). Overexpression of COX-2 leads to stimulation of mammary epithelial cell growth (Bandyopadhyay et al. 1987), increased biosynthesis of estrogens (Harris et al. 1999), and decreased immune surveillance (Huang et al. 1998). Additionally, expression of COX-2 leads to the production of mutagens (Howe et al. 2001), increased invasion, angiogenesis, and the inhibition of apoptosis (Liu et al. 1998; Gately 2000; Howe et al. 2001). The observations described here suggest that the rare foci of cells containing hypermethylated p16 promoters have the ability not only to accumulate genomic instability, but also to induce critical oncogenic phenotypes such as angiogenesis and inhibition of apoptosis. Thus, these cells represent a potent precursor population for oncogenic progression.

\section{POTENTIAL RELEVANCE OF vHMEC TO MALIGNANCY}

The above data demonstrate that a sizable fraction of women $(>30 \%)$ have a subpopulation of human mam- 
mary ductal and lobular epithelial cells containing hypermethylated $\mathrm{p} 16^{\mathrm{INK} 4 \mathrm{a}}$ promoter sequences and overexpression of COX-2. As noted before, hematoxylin and eosin staining of adjacent serial sections demonstrated that the cells containing the coincident overexpression of COX-2 and methylated p16 promoter sequences retained normal morphology as determined by pathologists. What is the relationship, if any, of these foci to the development of cancer? The first issue to address is that the fraction of women containing any frequency of foci exhibiting the "variant" characteristics is substantially higher than the fraction of women who are diagnosed with breast cancer. In addition, given that these determinations were done on a limited amount of tissue sampled from individual mammary glands, it may be that an even greater fraction of healthy women contain these foci, and/or the reservoir of these cells in healthy women is considerable. At the very least, this could indicate that not all of these foci progress to cancer. Since less than $30 \%$ of the population develops breast cancer, it could reasonably be argued that subsequent events are necessary for progression. Of course, alternatively, it could be that these cells do not relate to carcinogenesis at all and may represent some stem cell population or dead-end lineage.

Data exist for the progression of a fraction of less malignant lesions to more malignant ones. In this manner, fewer lesions at each stage would progress to the more advanced state. Using data generated from autopsy series, studies by Nielsen and colleagues (Nielsen et al. 1987) and Alpers and Wellings (1985), among others, shed light on the prevalence of undetected premalignant breast disease. In the Nielsen study of double mastectomy specimens from 110 medicolegal autopsies, whose cause of death was unrelated to breast cancer, nearly one-third of patients harbored hyperplastic lesions (UDH, 32\%), over one-quarter contained atypical ductal hyperplasia $(\mathrm{ADH}$, $27 \%$ ), almost one-fifth showed ductal carcinoma in situ (DCIS, 18\%), and 2\% had overt invasive breast cancer. Furthermore, almost half of the women with DCIS had bilateral (41\%) and/or multifocal (45\%) disease. Alpers and Wellings' study of 185 breast samples from random autopsies confirms this high prevalence of undetected premalignant breast lesions. Several other studies that sampled mastectomy tissue less frequently noted smaller numbers of premalignant lesions (Welch and Black 1997). Additionally, these numbers have been suggested to be high due to the difficulty in accurately diagnosing the various premalignant lesions. In the context of the observations made with the methylation of the $\mathrm{p} 16$ promoter in healthy women in vivo, one would hypothesize that the methylation event is an early molecular event and that subsequent events would contribute to the multistep progression of this population of nascent tumor cells through the premalignant stages. If this is so, the characterization of the in vitro vHMEC may provide molecular clues to the subsequent changes required for carcinogenesis.

If cells with variant characteristics do represent precursors to breast cancer, we would predict that some fraction of premalignant lesions would express the relevant characteristics. To test this hypotheis, we examined 65 cases of DCIS for the overexpression of COX-2 (Shim et al. 2003). We found that a large proportion of low- and highgrade DCIS overexpress COX-2 not only in the morphologically distinct DCIS lesion, but also in the adjacent surrounding morphologically normal epithelial cells. Studies are under way to assess the presence of cells with variant characteristics in even earlier premalignant lesions (see Fig. 5).

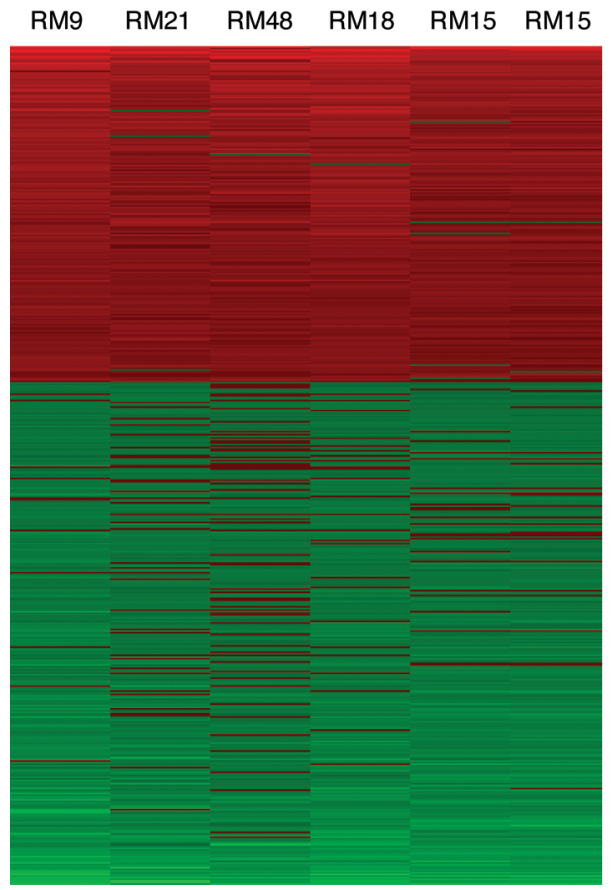

up

down

Heat map shows

517 out of 20948 gene changes distinguish vHMEC from HMEC
Figure 5. Gene expression profiling identifies a distinct subpopulation of cells in the human mammary gland. Tissues from five different women were processed for the generation of vHMEC populations and subjected to gene expression profiling. A signature of 517 gene changes identified the variant population of cells from the HMEC population. Of these changes, less than half are the result of p16 expression changes. 


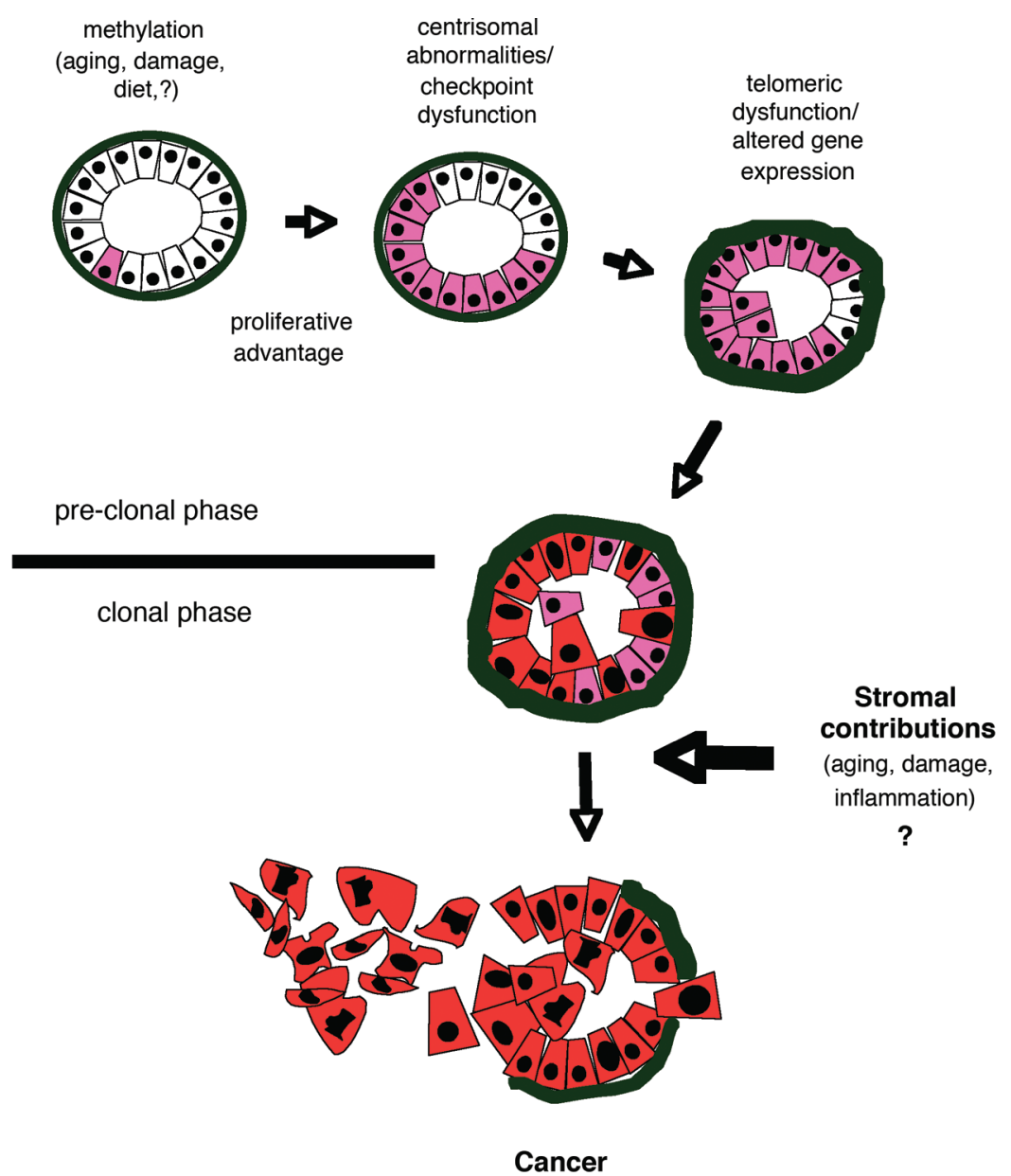

Figure 6. Model for breast cancer evolution.

\section{CONCLUSIONS}

We hypothesize that the above-described properties of HMEC in vitro are critically relevant to their transformation processes in vivo and may provide insights into controlling progression to cancer. In the model presented in Figure 6 , cells that contain hypermethylated p16 promoter sequences could continue to proliferate under conditions when the p16-expressing cells do not. Since continued proliferation of cells in the absence of p16 expression holds great potential for generating chromosomal abnormalities, this subpopulation of cells is free to accumulate mutations that may facilitate tumorigenesis. When the variant cells proliferate to the point of critically short telomeres, telomeric dysfunction fuels the generation of massive, random pre-clonal genomic instability to allow the emergence of clonal isolates that may progress to tumorigenicity. Selection pressures exerted by the microenvironment would be postulated to generate clonal isolates. The continuing telomeric and centrosomal dysfunction, coupled with the activation of pathways associated with overexpression of $\mathrm{COX}-2$, provides a potent package of events to promote tumorigenesis.

This alternative perception of the tumorigenic process differs from other perceptions in that it recognizes a dis- tinct subpopulation of cells which can be identified in an especially vulnerable stage of carcinogenesis that exists prior to the clonal outgrowth of tumorigenic cells. The majority of therapeutic targets at the present time address the consequences of genomic instability, such as the targeting of Gleevec to the Philadelphia chromosome translocation. Analysis of this model system may provide targets to address the process of genomic instability rather than its consequences.

\section{ACKNOWLEDGMENTS}

We gratefully acknowledge Dr. S. Lowe and Dr. G. Hannon for the gift of the shRNA p $16^{\text {INK4a }}$. We thank Dr. J. Salisbury for providing antibody for immunocytochemical detection of the centrosome-associated centrin protein (clone 20H5) and for the EGFP-CETN2 plasmid construct. We thank Dr. Alexey Khodjakov for the EGFP- $\gamma$-Tubulin plasmid construct. We thank Dr. W. Lingle and V. Negron for technical advice on immunocytochemical techniques. We thank J. Sedivy for the gift of human diploid fibroblasts with inactivated p21, and Karen Chew for help with human tissue acquisition. We thank Dr. W. Hyun for technical assistance with confocal 
microscopy and flow cytometry. We are also grateful to M. Stampfer for early technical assistance with cell culture. This work was supported by the Avon Foundation, The Cancer League, Inc., grant CA73952 from the National Institutes of Health/National Cancer Institute awarded to T.D.T., and funding from the California Breast Cancer Research Program. K.M.M. and H.B. were supported by funding from the George Williams Hooper Foundation training grant, and K.M.M. by a postdoctoral fellowship to the California Breast Cancer Research Program. C.A.F. was supported by funding from the Department of Defense.

\section{REFERENCES}

Alpers C.E. and Wellings S.R. 1985. The prevalence of carcinoma in situ in normal and cancer-associated breasts. Hum. Pathol. 16: 796.

Band V. and Sager R. 1989. Distinctive traits of normal and tumor-derived human mammary epithelial cells expressed in a medium that support long-term growth of both cell types. Proc. Natl. Acad. Sci. 86: 1249.

Bandyopadhyay G.K., Imagawa W., Wallace D., and Nandi S. 1987. Linoleate metabolites enhance the in vitro proliferative response of mouse mammary epithelial cells to epidermal growth factor. J. Biol. Chem. 262: 2750.

Baylin S.B. and Herman J.G. 2000. DNA hypermethylation in tumorigenesis: Epigenetics joins genetics. Trends Genet. 4: 168.

Benanti J.A. and Galloway D.A. 2004. Normal human fibroblasts are resistant to RAS-induced senescence. Mol. Cell. Biol. 24: 2842.

Berg J.W. and Hutter R.V. 1995. Breast cancer. Cancer 75: 257. Bodnar A.G., Ouellette M., Frolkis M., Holt S.E., Chiu C.P., Morin G.B., Harley C.B., Shay J.W., Lichtsteiner S., and Wright W.E. 1998. Extension of life-span by introduction of telomerase into normal human cells. Science 279: 349.

Boveri T. 1914. Zur Frage der Entstehung maligner Tumoren, vol. 4, p. 64. Gustav Fischer, Jena, Germany.

Boveri T.and Boveri M. 1929. The origin of malignant tumors. Williams and Wilkins, Baltimore, Maryland.

Brenner A.J., Stampfer M.R., and Aldaz C.M. 1998. Increased p16 expression with first senescence arrest in human mammary epithelial cells and extended growth capacity with p16 inactivation. Oncogene 17: 199.

Burbano R.R., Mederios A., deAmorin M.I., Lima E.M., Mello A., Neto J.B., and Casartelli C. 2000. Cytogenetics of epithelial hyperplasias of the human breast. Cancer Genet. Cytogenet. 119: 62 .

Cairns P., Mao L., Merlo A., Lee D.J., Schwab D., Eby Y., Tokino K., Van der Riet P., Blaugrund J.E., and Sidransky D. 1994. Rates of p16 (MTS1) mutations in primary tumors with 9p loss. Science 265: 415.

Crawford Y.G., Gauthier M.L., Joubel A., Mantei K., Kozakiewicz K., Afshari C.A., and Tlsty T.D. 2004. Histologically normal human mammary epithelia with silenced p16(INK4a) overexpress COX-2, promoting a premalignant program. Cancer Cell 5: 263.

Deng G., Lu Y., Zlotnikov G., Thor A.D., and Smith H.S. 1996. Loss of heterozygosity in normal tissue adjacent to breast carcinomas. Science 274: 2057.

Duensing S. 2005. A tentative classification of centrosome abnormalities in cancer. Cell Biol. Int. 29: 352.

Foster S.A. and Galloway D.A. 1996. Human papillomavirus type $16 \mathrm{E} 7$ alleviates a proliferation block in early passage human mammary epithelial cells. Oncogene 12: 1773.

Foster S.A., Wong D.J., Barrett M.T., and Galloway D.A. 1998. Inactivation of p16 in human mammary epithelial cells by CpG island methylation. Mol. Cell. Biol. 18: 1793.

Gately S. 2000. The contributions of cyclooxygenase-2 to tumor angiogenesis. Cancer Metastasis Rev. 19: 19.
Gonzalez-Zulueta M., Bender C.M., Yang A.S., Nguyen T., Beart R.W., Van Tornout J.M., and Jones P.A. 1997. Methylation of the $5^{\prime} \mathrm{CpG}$ island of the p16/CDKN2 tumor suppresor gene in normal and transformed human tissue correlates with gene silencing. Cancer Res. 55: 4531.

Hahn W.C., Counter C.M., Lundberg A.S., Beijersbergen R.L., Brooks M.W., and Weinberg R.A. 1999. Creation of human tumor cells with defined genetic elements. Nature 400: 464.

Hammond S.L., Ham R.G., and Stampfer M.R. 1984. Serumfree growth of human mammary epithelial cells: Rapid clonal growth in defined medium and extended passage with pituitary extract. Proc. Natl. Acad. Sci. 81: 5435.

Harris R.E., Robertson F.M., Abou-Issa H.M., Farrar W.B., and Brueggemeier R. 1999. Genetic induction and upregulation of cyclooxygenase (COX) and aromatase (CYP19): An extension of the dietary fat hypothesis of breast cancer. Med. Hypotheses 52: 291.

Hayflick L. 1965. The limited in vitro lifetime of human diploid cell strains. Exp. Cell Res. 37: 614.

Herman, J.G., Graff, J.R., Myöhänen S., Nelkin B.D., and Baylin S.B. 1996. Methylation-specific PCR: A novel PCR assay for methylation status of $\mathrm{CpG}$ islands. Proc. Natl. Acad. Sci. 93: 9821.

Herman J.G., Civin C.I., Issa J.P., Collector M.I., Sharkis S.J., and Baylin S.B. 1997. Distinct patterns of inactivation of p15INK4B and p16INK4A characterize the major types of hematological malignancies. Cancer Res. 57: 837.

Holst C.R., Nuovo G.J., Esteller M., Chew K., Baylin S.B., Herman J.G., and Tlsty T.D. 2003. Methylation of p16(INK4a) promoters occurs in vivo in histologically normal human mammary epithelia. Cancer Res. 63: 1596.

Howe L.R., Subbaramaiah K., Brown A.M., and Dannenberg A.J. 2001. Cyclooxygenase-2: A target for the prevention and treatment of breast cancer. Endocr. Relat. Cancer 8: 97.

Huang M., Stolina M., Sharma S., Mao J.T., Zhu L., Miller P.W., Wollman J., Herschmann D., and Dubinett S.M. 1998. Nonsmall cell lung cancer cyclooxygenase-2-dependent regulation of cytokine balance in lymphocytes and macrophages: Up-regulation of interleukin 10 and down-regulation of interleukin 12 production. Cancer Res. 58: 1208.

Huschtscha L.I., Noble J.R., Neumann A.A., Moy E.L., Barry P., Melki J.R., Clark S.J., and Reddel R.R. 1998. Loss of p16INK4 expression by methylation is associated with lifespan extension of human mammary epithelial cells. Cancer Res. 58: 3508 .

Jiang X.R., Jimenez G., Chang E., Frolkis M., Kusler B., Sage M., Beeche M., Bodnar A.G., Wahl GM., Tlsty T.D., and Chiu C.P. 1999. Telomerase expression in human somatic cells does not induce changes associated with a transformed phenotype. Nat. Genet. 21: 111.

Kao C.Y., Nomata K., Oakley C.S., Welsh C.W., and Chang C.C. 1995. Two types of normal human breast epithelial cells derived from reduction mammoplasty: Phenotypic characterization and response to SV40 transfection. Carcinogenesis 16: 531.

Kiyono T., Foster S.A., Koop J.I., McDougall J.K., Galloway D.A., and Klingelhutz A.J. 1998. Both Rb/p16INK4a inactivation and telomerase activity are required to immortalize human epithelial cells. Nature 396: 84 .

Krinferpot P., Quon K.C., Mooi W.J, Loonstra A., and Berns A. 2001. Loss of p16 Ink4a confers susceptibility to metastatic melanoma in mice. Nature 413: 83.

Lakhani S.R., Chaggar R., Davies S., Jones C., and Collins N. 1999. Genetic alterations in 'normal' luminal and myoepithelial cells of the breast. J. Pathol. 189: 496.

Larson P.S., de las Morenas A., Bennett S.R., Cupples L.A., and Rosenberg C.L. 2002. Loss of heterozygosity or allele imbalance in histologically normal breast epithelium is distinct from loss of heterozygosity or allele imbalance in co-existing carcinomas. Am. J. Pathol. 161: 283.

Larson P.S., de las Morenas A., Cupples L.A., Huang K., and Rosenberg C.L. 1998. Genetically abnormal clones in histologically normal breast tissue. Am. J. Pathol. 152: 1591.

Li Z., Moore D.H., Meng Z.H., Ljung B.M., and Gray J.W. 
2002. Increased risk of local recurrence is associated with allelic loss in normal lobules of breast cancer patients. Cancer Res. 62: 1000 .

Lingle W.L. and Salisbury J.L. 1999. Altered centrosome structure is associated with abnormal mitosis in human breast tumors. Am. J. Pathol. 155: 1941.

Lingle W.L., Barrett S.L., Negron V.C., D'Assoro A.B., and Boeneman K. 2002. Centrosome and amplification drives chromosomal instability in breast tumor development. Proc. Natl. Acad. Sci. 99: 1978.

Lingle W.L., Lutz W.H., Ingle J.N., Maihle N.J, and Salisbury J.L. 1998. Centrosome hypertrophy in human breast tumors: Implications for genomic stability and cell polarity. Proc. Natl. Acad. Sci. 95: 2950.

Liu X.H., Yao S., Kirschenbaum A., and Levine A.C. 1998. NS398, a selective cyclooxygenase-2 inhibitor, induces apoptosis and down-regulates bcl-2 expression in $\mathrm{LNCaP}$ cells. Cancer Res. 58: 4245.

Luria S.E. and Delbrück M. 1943. Mutations of bacteria from virus sensitivity to virus resistance. Genetics 28: 491.

Medema R.H., Herrera R.E., Lam F., and Weinberg R.A. 1995. Growth suppression by p16INK4 requires functional retinoblastoma protein. Proc. Natl. Acad. Sci. 92: 6289.

Nielsen M., Thomsen J.L., Primdahl S., Dyreborg U., and Andersen J.A. 1987. Breast cancer and atypia among young and middle-aged women: A study of 110 medicolegal autopsies. Br. J. Cancer 56: 814.

Nguyen C., Liang G., Nguyen T.T., Tsao-Wei D., Groshen S., Lübbert M., Zhou J.H., Benedict W.F., and Jones P.A. 2001. Susceptibility of nonpromoter CpG islands to de novo methylation in normal and neoplastic cells. J. Natl. Cancer Inst. 93: 1465.

Nuovo G.J., Plaia T.W., Belinsky S.A, Baylin S.B., and Herman J.G. 1999. In situ detection of the hypermethylation-induced inactivation of the p16 gene as an early event in oncogenesis. Proc. Natl. Acad. Sci. 96: 12754.

Pandis N. 1995. Chromosome abnormalities in bilateral breast carcinomas. Cytogenetic evaluation of the clonal origin of multiple primary tumors. Cancer 76: 250 .

Parry D. and Peters G. 1996. Temperature-sensitive mutants of p16 $6^{C D K N 2}$ associated with familial melanoma. Mol. Cell. Biol. 16: 3844 .

Ramirez R.D., Morales C.P., Herbert B.S., Rohde J.M., Passons C., Shay J.W., and Wright W.E. 2001. Putative telomere-independent mechanisms of replicative aging reflect inadequate growth conditions. Genes Dev. 15: 398.

Romanov S.R., Kozakiewicz B.K., Holst C.R., Stampfer M.R., Haupt L.M., and Tlsty T.D. 2001. Normal human mammary epithelial cells spontaneously escape senescence and acquire genomic changes. Nature 409: 633.

Salisbury J.L. 2001. The contribution of epigenetic changes to abnormal centrosomes and genomic instability in breast cancer. J. Mammary Gland Biol. Neoplasia 6: 203.

Serrano M., Hannon G.J, and Beach D. 1993. A new regulatory motif in cell-cycle control causing specific inhibition of cyclin D/CDK4. Nature 366: 704.

Sharpless N.E., Bardeesy N., Lee K.H., Carrasco D., Castrillon D.H, Aguirre A.J., Wu E.A., Horner J.W., and DePinho R.A. 2001. Loss of p16Ink4a with retention of p19Arf predisposes mice to tumorigenesis. Nature 413: 86.

Shim V., Gauthier M.L., Sudilovsky D., Mantei K., Chew K.L., Moore D.H., Cha I., Tlsty T.D., and Esserman L.J. 2003. Cyclooxygenase-2 expression is related to nuclear grade in ductal carcinoma in situ and is increased in its normal adjacent epithelium. Cancer Res. 63: 2347.

Stampfer M.R., Garbe J., Levine G., Lichtsteiner S., Vasserot A.P., and Yaswen P. 2001. Expression of the telomerase catalytic subunit, hTERT, induces resistance to transforming growth factor $\beta$ growth inhibition in $16^{\mathrm{INK} 4 \mathrm{a}}(-)$ human mammary epithelial cells. Proc. Natl. Acad. Sci. 98: 4498.

Taylor-Papadimitriou J., Stampfer M., Bartek J., Lewis A., Boshell M., Lane E.B., and Leigh I.M. 1989. Keratin expression in human mammary epithelial cells cultured from normal and malignant tissue: Relation to in vivo phenotypes and influence of medium. J. Cell Sci. 94: 403.

Tlsty T.D., Margolin B.H., and Lum K. 1989. Differences in the rates of gene amplification in nontumorigenic and tumorigenic cell lines as measured by Luria-Delbrück fluctuation analysis. Proc. Natl. Acad. Sci. 86: 9441.

Tlsty T.D., Romanov S.R., Kozakiewicz B.K., Holst C.R., Haupt L.M., and Crawford Y.G. 2001. Loss of chromosomal integrity in human mammary epithelial cells subsequent to escape from senescence. J. Mammary Gland Biol. Neoplasia 6: 235.

Tlsty T.D., Crawford Y.G., Holst C.R., Fordyce C.A., Zhang J., McDermott K., Kozakiewicz K., and Gauthier M.L. 2004. Genetic and epigenetic changes in mammary epithelial cells may mimic early events in carcinogenesis. J. Mammary Gland Biol. Neoplasia 9: 263.

Van Steensel B., Smogorzewska A., and de Lange T. 1998. TRF2 protects human telomeres from end-to-end fusions. Cell 92: 401.

Walen K.H. and Stampfer M.R. 1989. Chromosome analyses of human mammary epithelial cells at stages of chemical-induced transformation progression to immortality. Cancer Genet. Cytogenet. 37: 249.

Welch H.G. and Black W.C. 1997. Using autopsy series to estimate the disease "reservoir" for ductal carcinoma in situ of the breast: How much more breast cancer can we find? Ann. Intern. Med. 127: 1023.

Yang R., Serrano M., Slater J., Leung E., and Koeffler H.P. 1996. Analysis of p16INK4a and its interaction with CDK4. Biochem. Biophys. Res. Commun. 218: 254. 


\section{$8_{8}^{\infty} \mathrm{CSH} \&$ Cold Spring Harbor Symposia SYMPOSIA on Quantitative Biology}

\section{Genetic and Epigenetic Changes in Mammary Epithelial Cells Identify a Subpopulation of Cells Involved in Early Carcinogenesis}

H. BERMAN, J. ZHANG, Y.G. CRAWFORD, et al.

Cold Spring Harb Symp Quant Biol 2005 70: 317-327

Access the most recent version at doi:10.1101/sqb.2005.70.051

References This article cites 62 articles, 26 of which can be accessed free at: http://symposium.cshlp.org/content/70/317.full.html\#ref-list-1

\section{License}

Email Alerting Receive free email alerts when new articles cite this article - sign up in Service the box at the top right corner of the article or click here. 